ADLFI. Archéologie de la France -

\title{
Canton de Billom
}

Frédéric Trément

\section{OpenEdition \\ Journals}

Édition électronique

URL : http://journals.openedition.org/adlfi/4933

ISSN : 2114-0502

Éditeur

Ministère de la culture

Référence électronique

Frédéric Trément, «Canton de Billom », ADLFI. Archéologie de la France - Informations [En ligne], Auvergne, mis en ligne le 01 mars 2006, consulté le 03 mai 2019. URL : http://

journals.openedition.org/adlfi/4933

Ce document a été généré automatiquement le 3 mai 2019.

(c) Ministère de la Culture et de la Communication, CNRS 


\title{
Canton de Billom
}

\author{
Frédéric Trément
}

Identifiant de l'opération archéologique : 27

Date de l'opération : 2006 (EX)

1 La prospection systématique du canton de Billom, initiée en 2005, s'est poursuivie durant l'année 2006 (BSR 2005, p. 114-115). Deux stages universitaires, d'une durée de neuf jours chacun, ont été menés en février-mars et avril 2006. L'écartement maximum entre les prospecteurs est de $10 \mathrm{~m}$. Trois grandes zones ont été privilégiées cette année (Fig. $\mathrm{n}^{\circ} 1$ : Résultats de la campagne de prospection-inventaire 2006).

2 La première zone correspond à l'environnement proche du puy Benoît (communes de Chauriat, Chas et Billom), qui culmine à $539 \mathrm{~m}$. Les versants ont généralement livré peu de vestiges archéologiques, à l'exception des petits replats topographiques, comme par exemple celui situé au sud du "Château de Bard», sur la commune de Chauriat, où de multiples occupations ont été identifiées sur un vaste site (Préhistoire, Protohistoire, Antiquité). En revanche, la prospection des zones de bas de versants a mis en évidence de très nombreuses entités archéologiques préhistoriques, protohistoriques, antiques et médiévales. La période romaine est particulièrement bien représentée ; plusieurs types de sites ont été caractérisés, tels qu'une zone funéraire, de nombreux bâtiments plus ou moins importants et une très vaste villa.

3 La deuxième zone où les efforts se sont concentrés est située à l'est de Billom, sur les communes de Glaine-Montaigut et Égliseneuve-près-Billom. L'altitude des unités de prospection varie de $360 \mathrm{~m}$ à $500 \mathrm{~m}$. Ces zones de versants ont été intensivement fréquentées, dès la Préhistoire, mais là aussi c'est l'Antiquité qui a livré le plus de vestiges. Les conditions de prospections, relativement mauvaises, n'ont permis généralement que de reconnaître les sites sans qu'une chronologie fine puisse être établie. Il faut noter la découverte, sur la commune de Reignat, d'un vaste site (occupations laténienne et romaine) où ont été ramassées plusieurs centaines de scories de fer et plusieurs dizaines de culots ferreux. Ce site, particulièrement étendu, laisse 
penser à un habitat groupé. Une nouvelle prospection sera menée en 2007 dans ce secteur, afin de caractériser l'environnement proche de cet établissement.

4 La troisième zone est localisée sur la commune de Saint-Julien-de-Coppel, au nord du petit hameau du Boisseret. Malgré la faible superficie prospectée dans ce secteur, trois sites ont déjà été identifiés (un protohistorique et deux datés du Haut-Empire).

Enfin, la poursuite du parcours systématique des chemins de la zone d'étude a permis de repérer quatre sites et un indice de site qui seront caractérisés plus finement en 2007, de même que les sites photographiés au cours des prospections aériennes (neuf sites repérés en 2006 sur le secteur d'étude).

6 Au total, la prospection systématique réalisée en 2006 aura permis de couvrir une surface de 535 ha et de repérer 45 sites et 14 indices de sites.

7 Frédéric Trément

\section{ANNEXES}

Fig. $\mathrm{n}^{\circ} 1$ : Résultats de la campagne de prospection-inventaire 2006

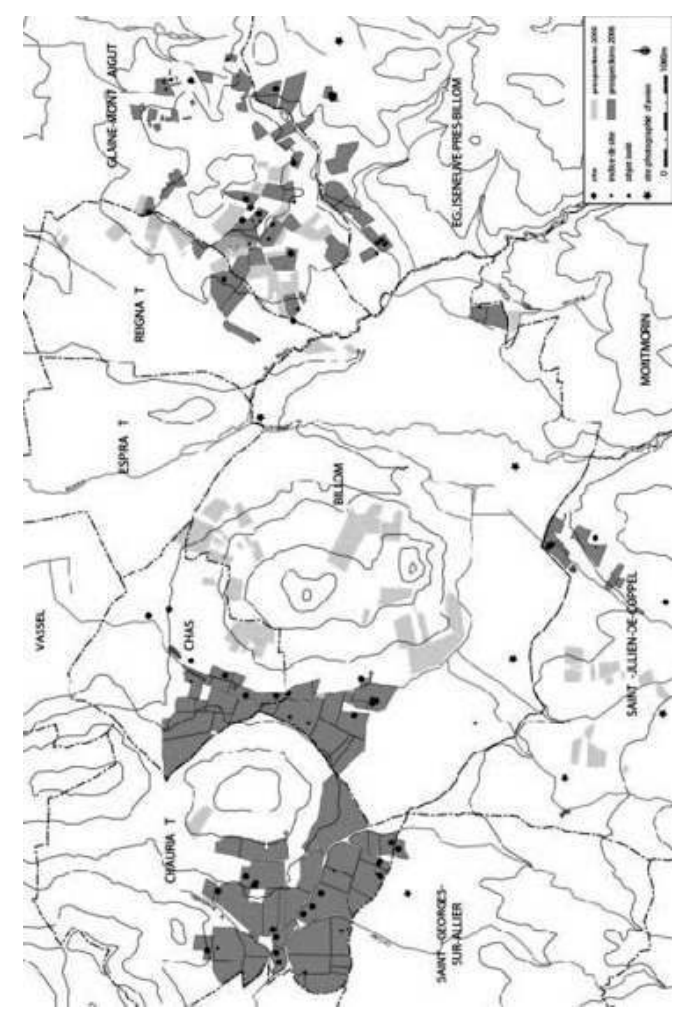

Auteur(s) : Trément, Frédéric (SUP). Crédits : Trément Frédéric, SUP (2006) 
INDEX

Index géographique : Auvergne, Puy-de-Dôme (63), Billom

Index chronologique : âge du Bronze, âge du Fer, Empire romain, Moyen Âge, Préhistoire

Thèmes : culot, édifice, édifice funéraire, fer, habitat groupé, occupation du sol, prospection aérienne, scories, villa

operation Expertise (EX)

AUTEURS

FRÉDÉRIC TRÉMENT

SUP 